\title{
Faecal Transplantation, Pro- and Prebiotics in Parkinson's Disease; Hope or Hype?
}

\author{
T. Van Laar ${ }^{\mathrm{a}, *}$, J.M. Boertien ${ }^{\mathrm{a}}$ and A. Horta Herranz ${ }^{\mathrm{b}}$ \\ ${ }^{a}$ Department of Neurology, University Medical Center Groningen, University of Groningen, The Netherlands \\ ${ }^{\mathrm{b}}$ Behavioral and Cognitive Neurosciences, University of Groningen, The Netherlands
}

\begin{abstract}
Faecal microbiome transplantation (FMT) is an attractive technique, because the administration is relatively simple and in general has a mild adverse effect pattern. Moreover, FMT consists of a broad mixture, which could be beneficial, because at this moment it is not known what type of changes in the microbiome are needed. However, except from a few cases no clinical data in Parkinson's disease (PD) is available yet. There is some indication that FMT might be beneficial in severe constipated PD patients, but the clinical data to support this are very scarce. So, actually there are no good data in the public domain to support FMT at this moment in PD patients. FMT at this moment is a black box with too many unanswered questions, also with respect to safety concerns. Only the administration of species of Lactobacillus and Bifidobacterium over a time period of four to twelve weeks has repeatedly proven to be effective in treating constipation in PD. Also, no solid clinical data are available about the possible effects of probiotic treatment on motor symptoms or progression of PD. Therefore, also probiotic treatments in PD should wait until better clinical data become available, in order to select the right target populations and to have good estimates of the clinical effects to be expected.
\end{abstract}

Keywords: Parkinson's disease, faecal microbiome transplantation, prebiotics, probiotics

\section{INTRODUCTION}

Gut dysbiosis has become an important theme in neuroscience. In particular, a recent publication indicating the gut microbiota of Parkinson's disease (PD) patients to influence alpha-synuclein (aSyn) aggregation in mice, has raised interest in this topic [1]. This study illustrates how gene-dependent overexpression of alpha-synuclein (genetic factor) critically interacts with gut microbiota (environmental factor) to produce the PD phenotype. Besides PD, microbiome changes have been correlated to numerous brain disorders like autism, anxiety, Alzheimer's disease (AD) and multiple sclerosis (MS) [2-4]. However, the most extensive data on gut dysbiosis are, however, derived from multiple PD cohorts [5-11]. All studies reported differences in composition between

\footnotetext{
${ }^{*}$ Correspondence to: Prof. dr. T. van Laar, neurologist, Hanzeplein 1, 9713GZ Groningen, The Netherlands. E-mail: t.van.laar@ umcg.nl.
}

PD patients and matched healthy controls, albeit with an incongruent picture across these studies. Despite this variance, some overlap could be detected, like an increased abundance of Lactobacillaceae, Akkermansia, Enterobacteriaceae and Bifidobacterium, and a decreased presence of Prevotellaceae, Faecalibacterium and Lachnospiraceae.

The question remains whether the current knowledge on microbiome changes in PD is sufficient to inform clinical trial design for microbial therapeutic interventions in PD.

\section{METABOLIC CONSEQUENCES OF GUT MICROBIOME CHANGES IN PD}

To evaluate possible therapeutic interventions, we have to understand the metabolic consequences of the described microbiome changes in PD.

Most of the above mentioned gut bacteria have been related to PD through their metabolic products, their interaction with the intestinal wall or their 
involvement in the gut hormonal balance. Short chain fatty acids (SCFA) are generated in the gut through fermentation of dietary fibers, and are thought to play a major role in the regulation of microbiome-gut-brain axis interactions. Bacteria that produce SCFA's include, but are not limited to, Bacteroides, Bifidobacterium, Propionibacterium, Eubacterium, Lactobacillus, Clostridium, Roseburia, and Prevotella $[12,13]$. Some SCFA (e.g. butyrate, produced by bacteria of the genera Blautia, Coprococcus, and Roseburia (family Lachnospiraceae) are putatively anti-inflammatory [6]. Reduced production of SCFA, for instance by a reduced amount of Lachnospiraceae, could therefore promote inflammatory responses, contributing to neurodegeneration [14-16]. The fact that faeces from PD patients contain lower amounts of SCFA [9] and show increased levels of intestinal inflammation, supports this hypothesis $[17,18]$.

SCFA play an important role in the regulation of immune function, more specifically on promoting the maturation of microglia [16, 19]. SCFA, like butyrate and acetate, may also increase mucin secretion, whereas bacterial species belonging to the genus Akkermansia, which is increased in PD, are known to degrade mucin [20-23]. Mucin lubricates the gut wall and maintains a barrier between epithelial cells and most microbes and toxins on the luminal surface of the gut $[24,25]$. Reduced mucin synthesis has been associated with increased gut permeability, which could culminate in aSyn pathology through increased exposure of the host to environmental stressors in the gut $[26,27]$. Therefore, the effect of decreased levels of SCFA could be potentiated by the decreased mucin levels, as a consequence of the microbiome changes in PD. In accordance, gut permeability was found to be increased in PD, though these findings have to be replicated in larger samples and might be restricted to subpopulations of PD patients [28]. SCFA's like propionate also have a direct influence on the blood-brain barrier (BBB), protecting the BBB from oxidative stress [29].

Besides the production of SCFA, Prevotellaceae is also involved in the biosynthesis of thiamine (vitamin B1) and folate (B9), which are both reduced in PD patients [30, 31]. Vitamin B1 is required as a cofactor in brain oxidative metabolism, and is found in high levels in the substantia nigra [32]. At the same time, decreased concentrations of striatal dopamine correlate with B1 deficiency, whereas intrastriatal $\mathrm{B} 1 \mathrm{administration}$ increases dopamine release in rats [33].
Decreased abundance of Prevotellaceae and increased Lactobacilliceae are associated with lower ghrelin levels [34]. This is supported by the fact that the levels of ghrelin are already found to be decreased in early stages of PD $[35,36]$. Ghrelin is a gut hormone which promotes healthy dopaminergic cell function in the SN, but also stimulates appetite and gastric motility, as well as the secretion of insulin and growth hormone. The secretion of ghrelin is influenced by gut dysbiosis.

Finally, many species of bacteria in the family Enterobacteriaceae have been associated with PD, putatively due to their production of hydrogen [11]. Drinking hydrogen water was shown to alleviate PD symptoms in mice, rats, and humans [37-39]. However, this is not in line with their relative overabundance in PD patients, as reported previously $[5,9]$. Only one study reported on the total count of putative hydrogen-producing bacteria in PD subjects to healthy controls (HC) and found the sum of putative hydrogen-producing bacteria to be lower [11].

So, overall the attempts to unravel a clear-cut microbiome composition that is strongly correlated with $\mathrm{PD}$, have produced a drizzle of partially reproducible changes in the PD microbiome. The studies do not converge on a specific signature or metabolic pathway for $\mathrm{PD}$, which is not surprising taking into account the variability and the difficulty of cataloging the amount, roles and components of human gut commensals, which has led to large cooperative efforts like the Human Microbiome Project [40].

\section{GUT MICROBIOME CHANGES IN OTHER NEUROLOGICAL DISORDERS}

We have to realize that microbiome changes also have been found in other neurological and neurodevelopmental disorders, which raises questions about causality and the specificity of the changes for a given disease or a group of disorders $\mathrm{In} \mathrm{AD}$ increases in Escherichia/Shigella abundance, together with decreases in E. rectale abundance were associated with a peripheral inflammatory state [41]. Others reported a lower microbial diversity in $\mathrm{AD}$, distinct from matched controls, together with a decrease in Firmicutes and Bifidobacterium and an increase in Bacteroidetes [42]. Children with autism spectrum disorder showed lower levels of Bifidobacterium and Firmicutes and higher levels of Lactobacillus, Clostridium, and Bacteroidetes [43-45]. In MS 
patients higher abundances of Methanobrevibacter (Archaea) and Akkermansia and lower Butyricimonas were found [46]. Other MS studies recurrently found subtle differences between MS and control microbiome [47-50]. Despite specific changes (eg. increased Bifidobacterium), differentiating the PD microbiome from other neurological disorders, a considerable overlap between the microbiome signatures of the various disorders remains. Questions regarding the specificity and the causality of these findings should therefore ideally be addressed across multiple disorders, trying to correlate the microbiome changes not only to disorders, but also to common underlying disease characteristics, like central nervous system (CNS) inflammation, gut permeability, reduced levels of vitamin B1 and B9, reduced levels of ghrelin, or reduced levels of hydrogen. The most promising of these mechanisms seem to be SCFA-mediated gut-brain communication, due to the extensive research on the subject and the robust relation between inflammation and neurodegeneration [51]. On the other hand, mucin-producing (or mucin-degrading) bacteria and PD are related by many indirect associations (between bacteria abundance and low mucin, between low mucin and a leaky gut, and, lastly, between a leaky gut and PD), while the research on the role of hydrogen in PD, as well as on the connection between ghrelin and Lactobacilliceae/Prevotella abundance is scarce and doesn't justify any conclusions yet.

\section{METHODOLOGICAL LIMITATIONS OF EXISTING STUDIES ON THE MICROBIOME IN PD}

In spite of having uncovered some potentially relevant connections between specific bacteria and PD pathophysiology, these case-control studies face clear limitations. The first one is that case-control settings do not enable causal connections. These studies can only provide correlational evidence and cannot exclude reverse causation (they cannot exclude the possibility that PD itself results in dysbiosis/constipation). Also, the influence of possible confounders of gut microbiome composition was often inadequately assessed. An important confouder is the presence and or severity of constipation. Constipation might be the origin, as well as a promotor, or even a consequence of microbiome changes or PD [52-54]. Microbiome studies on patients suffering from idiopathic constipation report several changes, like a decrease in obligate bacteria (e.g. Lactobacillus, Bifidobacterium, and Bacteroides spp.) and a parallel increase of potentially pathogenic micro-organisms (e.g. Pseudomonas aeruginosa and Campylobacter jejuni) [55], which are different from the microbiome changes described in PD. This disparity could be interpreted as evidence that constipation very likely is not the start of PD-related microbiome changes, i.e. chronic constipation creates a specific microbiome configuration and PD another. Only a longitudinal, prodromal-PD cohort, matched with a control group in terms of presence and severity of constipation, ideally measured using objective markers of the stool transit time, will be able to answer this question on the role of constipation in the development of PD. Another important confounder could be the dopaminergic medication, only present in the PD group, stressing the need for an assessment of gut microbiome changes in a treatment-näive cohort $[56,57]$. These examples show that results of the different studies are difficult to compare, because their assessment methods and adjustment for confounders is not consistent. Moreover, most studies had relatively small sample sizes, which further complicates comparing and integrating results.

Besides possible confounders within the study population, technical confounders can arise like different methods of sample collection, shipment, storage, DNA extraction, sequencing, bioinformatical analysis and statistical analysis, which are known to drive artificial differences in gut microbiome composition studies in general [58]. Also across microbiome studies in PD, various different methodological approaches have been deployed [57].

Finally, the current microbiome studies predominantly looked at bacterial species, but hardly included archaea, yeast and viruses, which are also an integral part of the intestinal flora [7]. PD patients f.i. show shifts of the bacteriophage(virus)/bacteria ratio for Lactobacilliceae [59]. This route should be part of future investigations.

\section{FAECAL TRANSPLANTATION IN PD}

One way to restore eubiosis in the gut of patients is by means of fecal microbiota transplantation (FMT). FMT consists of transferring liquid filtrate faeces from a healthy, screened individual to a patient via nasogastric or nasoduodenal tube, enema, or colonoscope. Little is known about the differences in long-term effects in relation to the route of adminis- 
tration. From a physiological perspective, one would suggest that a proximal-distal spreading of transplanted microbiota seems to be the most natural route. However, no comparative data are available to support one route in special. FMT has shown a high success rate $(85-90 \%)$ in the short term treatment of Clostridium Difficile infections, together with low-risk and short-term adverse effects, most commonly bloating, abdominal pain, diarrhea and/or constipation $[60,61]$. Since a few years back, this attractive combination of high success rate and low risk in treatment of C. Difficile infections has fueled the interest on applying FMT to treat patients with various conditions, like inflammatory bowel disease (IBD) or idiopathic constipation [62, 63]. Currently, many have proposed to target non-gastrointestinal disorders like autism, MS, or PD, with FMT [64]. However, references to the potential use of FMT in PD are restricted to a recent Chinese case study on a PD patient with severe constipation. The constipation as well as his PD symptoms greatly improved after FMT [65].

Consequently, the best available source of confidence on FMT as possible treatment for PD are the amalgam of studies discussed in the previous sections, which connect the gut microbiome to PD in various ways. The most compelling are probably murine studies where microbiome transplantations are carried out [66]. These studies mimic the FMT procedure with arguably successful results for the model PD mice, indicating that FMT might work in humans in spite of our incomplete insight in its specific mechanisms.

The first clinical trial on the use of FMT in PD patients is now on-going at the university of Ghent (Belgium) and is scheduled to be completed at the end of this year (2019) [67]. This clinical trial aims to recruit forty PD patients, with follow-up intervals of 3 months, up to one year, assessing the development of PD symptoms. The patients will receive FMT from healthy donors, whereas a control group will receive autologous FMT. The inclusion criteria for PD patients do not in- or exclude constipation, which may complicate the interpretation of results.

However, the definition of a healthy donor very likely is not sufficient to find an optimal donor for a specific PD patient at this moment, because FMT is still in its infancy. The lack of large randomized controlled clinical trials of FMT for the treatment of chronic diseases has meant that many observations, such as the existence of FMT super-donors, are not yet robustly supported by empirical evidence
[68]. Considerable effort has been spent in identifying the various factors which contribute to FMT success. In a broad sense, high diversity of the gut microbiota, particularly in the donor, appears to predict a patient's response to FMT most optimally [68]. More specifically, the efficacy of FMT likely depends on the ability of the donor to provide the necessary taxa capable of restoring metabolic deficits in recipients that are contributing toward disease. However, donor-recipient compatibility also plays an influential role in determining FMT success. Donor-recipient compatibility can stem from genetic factors such as differences in innate immune responses, or environmental factors including diet, xenobiotic exposure, and microbial interactions [68].

Further characterization of super-donors will likely result in the development of more refined FMT formulations to standardize therapy and reduce variability in patient response. In parallel, continued optimization of FMT protocols, including a shift toward capsule-based approaches, will help to combat the longevity issues associated with FMT and create a more patient-friendly alternative to current disease management schemes.

The great success of FMT in treating C. Difficile is most probably related to the fact that C.Difficile infections are a type of dysibiosis with a clear cause (i.e. overgrowth of C. Difficile), which is not influenced by other major contributors to the disorder. This is completely different in PD patients, with different subtypes, not knowing which subtype might be related to gut dysbiosis, and even not knowing if the gut dysbiosis is causal to the disease or not. In case a causal microbial factor in PD would be identified, it is paramount to identify the relevant PD subgroups in which this factor could be a genuine therapeutic target. This must be done either through a direct assessment of gut microbiome composition or the rapid quantification of taxa of interest, or indirectly through the identification of possible clinical subtypes associated with the relevant enterotype. Moreover, even if we would know which PD subtypes are eligible for a possible FMT treatment, it is not clear whether FMT treatment in the "late" motor stages of the disease will still exert a beneficial effect, as the synucleinopathy is already established in the CNS. Although there is direct signaling between the gut microbiota and the CNS that modulates the neuropathology in a rodent PD model, it is unclear whether this can still ameliorate the deleterious effects of an already established synucleinopathy [1]. 
Besides these uncertainties, there are still unresolved practical issues associated with FMT. FMT replaces the luminal microbiome, but very likely not the mucosal microbiome, which is different from the luminal microbiome, and arguably more long-standing [69]. Additionally, the influence of age, dietary habits of the donor, handling of the stool transplant, elimination of particular microbes, and the optimal volume of the transplant, as well the optimal frequency of transplantation is still unclear in case of FMT in PD patients [70, 71].

\section{PRO- AND PREBIOTICS IN PD}

Another method to restore eubiosis in the gut is the administration of probiotic mixtures. Probiotics are microbes with a perceived beneficial effect on intestinal and overall health, often administered in supplements, yoghurts or other fermented foods. In PD, administration of species of Lactobacillus and Bifidobacterium over a time period of four to twelve weeks has repeatedly proven to be effective in treating constipation [72-74]. Only one study addressed the change in motor- and non-motor symptoms after twelve weeks of treatment with species from the same genera [74]. Patients being treated with probiotics showed an improved motor score compared to placebo-treated patients, as well as a reduction of clinical signs of inflammation and oxidative stress compared to placebo-treated patients. However, all patients were only assessed after the probiotic intervention and not before. So, a solid baseline was lacking, which make these data difficult to interprete. Actually, referring to the microbiome studies in different PD cohorts, suppletion with Lactobacillus and Bifidobacterium does not look very rational, because both species have shown increased abundances in different populations.

FMT may have some advantages over probiotics, because the filtrates contain a more complex, complete, and stable assortment of intestinal microorganisms together with other substances (i.e. specific vitamins, bile acids) that might help to restore and maintain eubiosis, which is not the case in selected probiotics [75]. However, given the fact that FMT most likely only renews the luminal and not the mucosal microbiome, the transplanted stool may be washed out before it can foster eubiosis or a deeper change in the mucosal microbiome. Probiotics, on the other hand, can be administered for longer periods, their effect could be more targeted and might be more long- lasting.

Contrary to probiotics, prebiotics do not contain live microbes, but consists of dietary fibers that serve to feed perceived beneficial microbes. Prebiotics have not been used so far in clinical trials with PD patients. Only a few PD-animal models have used oral administered sodium butyrate, which indicated beneficial effects on the PD symptoms [76]. It is unclear however if it is better to use butyrate itself or fibers generating butyrate locally in the gut.

\section{RISKS OF GUT MICROBIAL INTERVENTIONS IN PD}

Despite their benign reputation, faecal transplantation, probiotics and prebiotics can pose a health risk when used as a treatment intervention. Recently, the US Food and Drug Administration gave out a warning after an extended-spectrum beta-lactamase E. Coli infection in two immuno-compromised adults who received FMT, one of which died (June 2019) [77]. In addition, the infamous "PROPATRIA" study (PRObiotics in PAncreatitis TRIAl) showed the potential deleterious effects of a probiotic treatment, consisting of six different strains of freeze-dried, viable bacteria: Lactobacillus acidophilus, Lactobacillus casei, Lactobacillus salivarius, Lactococcus lactis, Bifidobacterium bifidum, and Bifidobacterium lactis (previously classified as Bifidobacterium infantis), in a total daily dose of 1010 bacteria, plus cornstarch and maltodextrins [78]. This randomized controlled trial resulted in a significantly increased mortality in the treated group versus the placebo group. Also other studies indicated adverse effects, including lifethreatening conditions such as sepsis [79]. Although these deleterious effects can be ascribed to critically ill and often immune-compromised patients, they do support the intuitive notion that if gut microbiota can have both positive and negative health effects, gut microbial interventions can do the same.

For PD, the identification of beneficial microbes becomes even more complex, as the identified microbial shifts sometimes seem counter-intuitive compared to what is perceived as a healthy state of the gut microbiome in general. For example, the relative abundance of Lactobacillaceae and Bifidobacteria, two taxa generally associated with gastrointestinal health and often found in probiotic mixtures, seem to be increased in PD. Whether this represents an absolute increase remains to be seen, but on the one 
hand it begs the question if further suppletion with probiotics will be beneficial for PD patients. On the other hand, the increased levels of Lactobacillaceae and Bifidobacteria might represent a compensatory mechanism that could be disturbed if these levels are normalized by for instance the introduction of a "healthy" microbiome via FMT. Also, the role of microbial metabolites in PD sparks controversy. For example, SCFA have been described above as generally beneficial for gut microbial health and to exert an anti-inflammatory role. However, the seminal paper of Sampson et al. describes how the introduction of SCFA worsened the neuroinflammation and the PD phenotype in their rodent PD model [1].

Despite the current ambiguity of PD microbiome studies and the lack of solid functional evidence on the causality and direction of the presented differences, the hype surrounding gut microbial interventions in PD has already entered the neurological consultation. Often sparked by companies that supply probiotic supplements that should support gut microbial health in the general sense, patients are understandably interested in the possibility of gut microbial interventions for PD. Physicians should be aware that these treatments are offered to their patients by external parties, but are in no way tailored to the PD gut microbiome and might therefore be more harmful than beneficial, given the lack of well-designed trials to assess their effectiveness and risk profile in PD.

\section{CONCLUSIONS}

FMT is an attractive technique, because the administration is relatively simple and in general has a mild adverse effect pattern. Moreover, FMT consists of a broad mixture, which could be beneficial, because at this moment it is not known what type of changes in the microbiome are needed. However, except from a few cases, no clinical data in PD is available. There is some indication that FMT might be beneficial in severe constipated patients, but again, the clinical data to support this are very scarce. We think that it would be better to wait for the results of the ongoing trials, in order to shape future protocols, instead of performing new trials without good evidence how to design these. FMT at this moment is a black box with too many unanswered questions.

The current data on probiotic treatment in PD are even less indicative, so new trials should wait until more data on microbiome changes in PD become available.
In conclusion, there is hope for FMT being developed as a useful treatment for specific subgroups of PD patients, but at this moment there is too much hype around FMT as a therapeutic target in PD.

\section{REFERENCES}

[1] Sampson TR, Debelius JW, Thron T, Janssen S, Shastri GG, Ilhan ZE, Challis C, Schretter CE, Rocha S, Gradinaru V, Chesselet M-F, Keshavarzian A, Shannon KM, KrajmalnikBrown R, Wittung-Stafshede P, Knight R, Mazmanian SK (2016) Gut microbiota regulate motor deficits and neuroinflammation in a model of Parkinson's disease. Cell 167, 1469-1480.e12.

[2] Tabouy L, Getselter D, Ziv O, Karpuj M, Tabouy T, Lukic I, Maayouf R, Werbner N, Ben-Amram H, Nuriel-Ohayon M, Koren O, Elliott E (2018) Dysbiosis of microbiome and probiotic treatment in a genetic model of autism spectrum disorders. Brain Behav Immun 73, 310-319.

[3] Lach G, Schellekens H, Dinan TG, Cryan JF (2018) Anxiety, depression, and the microbiome: A role for gut peptides. Neurotherapeutics 15, 36-59.

[4] Kowalski K, Mulak A (2019) Brain-gut-microbiota axis in Alzheimer's disease. J Neurogastroenterol Motil 25, 48-60.

[5] Scheperjans F, Aho V, Pereira PAB, Koskinen K, Paulin L, Pekkonen E, Haapaniemi E, Kaakkola S, Eerola-Rautio J, Pohja M, Kinnunen E, Murros K, Auvinen P (2015) Gut microbiota are related to Parkinson's disease and clinical phenotype. Mov Disord 30, 350-358.

[6] Keshavarzian A, Green SJ, Engen PA, Voigt RM, Naqib A, Forsyth CB, Mutlu E, Shannon KM (2015) Colonic bacterial composition in Parkinson's disease. Mov Disord 30, 13511360 .

[7] Bedarf JR, Hildebrand F, Coelho LP, Sunagawa S, Bahram M, Goeser F, Bork P, Wüllner U (2017) Functional implications of microbial and viral gut metagenome changes in early stage L-DOPA-nä̈ve Parkinson's disease patients. Genome Med 9, 39.

[8] Hill-Burns EM, Debelius JW, Morton JT, Wissemann WT, Lewis MR, Wallen ZD, Peddada SD, Factor SA, Molho E, Zabetian CP, Knight R, Payami H (2017) Parkinson's disease and Parkinson's disease medications have distinct signatures of the gut microbiome. Mov Disord 32, 739749.

[9] Unger MM, Spiegel J, Dillmann K-UU, Grundmann D, Philippeit H, Bürmann J, Faßbender K, Schwiertz A, Schäfer K-HH (2016) Short chain fatty acids and gut microbiota differ between patients with Parkinson's disease and age-matched controls. Park Relat Disord 32, 66-72.

[10] Heintz-Buschart A, Pandey U, Wicke T, Sixel-Döring F, Janzen A, Sittig-Wiegand E, Trenkwalder C, Oertel WH, Mollenhauer B, Wilmes P (2018) The nasal and gut microbiome in Parkinson's disease and idiopathic rapid eye movement sleep behavior disorder. Mov Disord 33, 8898.

[11] Hasegawa S, Goto S, Tsuji H, Okuno T, Asahara T, Nomoto K, Shibata A, Fujisawa Y, Minato T, Okamoto A, Ohno K, Hirayama M (2015) Intestinal dysbiosis and lowered serum lipopolysaccharide-binding protein in Parkinson's disease. PLoS One 10, e0142164.

[12] Caspani G, Swann J (2019) Small talk: Microbial metabolites involved in the signaling from microbiota to brain. Curr Opin Pharmacol 48, 99-106. 
[13] Macfarlane GT, Macfarlane S Bacteria, colonic fermentation, and gastrointestinal health. (n.d.) JAOAC Int 95, 50-60.

[14] Caggiu E, Arru G, Hosseini S, Niegowska M, Sechi G, Zarbo IR, Sechi LA (2019) Inflammation, infectious triggers, and Parkinson's disease. Front Neurol 10, 122.

[15] Deleidi M, Gasser T (2013) The role of inflammation in sporadic and familial Parkinson's disease. Cell Mol Life Sci 70, 4259-4273.

[16] Erny D, De Angelis ALH, Jaitin D, Wieghofer P, Staszewski O, David E, Keren-Shaul H, Mahlakoiv T, Jakobshagen K, Buch T, Schwierzeck V, Utermöhlen O, Chun E, Garrett WS, Mccoy KD, Diefenbach A, Staeheli P, Stecher B, Amit I, Prinz M (2015) Host microbiota constantly control maturation and function of microglia in the CNS. Nat Neurosci 18, 965-977.

[17] Devos D, Lebouvier T, Lardeux B, Biraud M, Rouaud T, Pouclet H, Coron E, Bruley des Varannes S, Naveilhan P, Nguyen JM, Neunlist M, Derkinderen P (2013) Colonic inflammation in Parkinson's disease. Neurobiol Dis 50, 42-48.

[18] Houser MC, Chang J, Factor SA, Molho ES, Zabetian CP, Hill-Burns EM, Payami H, Hertzberg VS, Tansey MG (2018) Stool immune profiles evince gastrointestinal inflammation in Parkinson's disease. Mov Disord 33, 793-804.

[19] Cryan JF, Dinan TG (2015) Gut microbiota: Microbiota and neuroimmune signalling-Metchnikoff to microglia. Nat Rev Gastroenterol Hepatol 12, 494-496.

[20] Barcelo A, Claustre J, Moro F, Chayvialle JA, Cuber JC, Plaisancié P (2000) Mucin secretion is modulated by luminal factors in the isolated vascularly perfused rat colon. Gut 46, 218-224.

[21] Gaudier E, Rival M, Buisine M-P, Robineau I, Hoebler C (2009) Butyrate enemas upregulate Muc genes expression but decrease adherent mucus thickness in mice colon. Physiol Res 58, 111-119.

[22] Scheppach W, Sommer H, Kirchner T, Paganelli GM, Bartram P, Christl S, Richter F, Dusel G, Kasper H (1992) Effect of butyrate enemas on the colonic mucosa in distal ulcerative colitis. Gastroenterology 103, 51-56.

[23] Derrien M, Vaughan EE, Plugge CM, de Vos WM (2004) Akkermansia muciniphila gen. nov., sp. nov., a human intestinal mucin-degrading bacterium. Int J Syst Evol Microbiol 54, 1469-1476.

[24] Allen A, Flemström G (2005) Gastroduodenal mucus bicarbonate barrier: Protection against acid and pepsin. Am J Physiol Physiol 288, C1-C19.

[25] Pelaseyed T, Bergström JH, Gustafsson JK, Ermund A, Birchenough GMH, Schütte A, van der Post S, Svensson F, Rodríguez-Piñeiro AM, Nyström EEL, Wising C, Johansson ME V, Hansson GC (2014) The mucus and mucins of the goblet cells and enterocytes provide the first defense line of the gastrointestinal tract and interact with the immune system. Immunol Rev 260, 8-20.

[26] Robinson K, Deng Z, Hou Y, Zhang G (2015) Regulation of the intestinal barrier function by host defense peptides. Front Vet Sci 2, 57.

[27] Forsyth CB, Shannon KM, Kordower JH, Voigt RM, Shaikh M, Jaglin JA, Estes JD, Dodiya HB, Keshavarzian A (2011) Increased intestinal permeability correlates with sigmoid mucosa alpha-synuclein staining and endotoxin exposure markers in early Parkinson's disease. PLoS One 6, e28032.

[28] Clairembault T, Leclair-Visonneau L, Coron E, Bourreille A, Le Dily S, Vavasseur F, Heymann M-F, Neunlist M, Derkinderen P (2015) Structural alterations of the intestinal epithelial barrier in Parkinson's disease. Acta Neuropathol Commun 3, 12.

[29] Hoyles L, Snelling T, Umlai U-K, Nicholson JK, Carding SR, Glen RC, McArthur S (2018) Microbiome-host systems interactions: Protective effects of propionate upon the blood-brain barrier. Microbiome 6, 55 .

[30] Lu'o'ng K vinh quôc, Nguyên LTH (2012) Thiamine and Parkinson's disease. J Neurol Sci 316, 1-8.

[31] Luong KVQ, Nguyễn LTH (2013) The beneficial role of thiamine in Parkinson disease. CNS Neurosci Ther 19, 461468.

[32] Baker H, Frank O, Chen T, Feingold S, DeAngelis B, Baker E (1984) Vitamin content of some normal human brain segments. J Neurosci Res 11, 419-435.

[33] Yamashita H, Zhang Y-X, Nakamura S (1993) The effects of thiamin and its phosphate esters on dopamine release in the rat striatum. Neurosci Lett 158, 229-231.

[34] Queipo-Ortuño MI, Seoane LM, Murri M, Pardo M, GomezZumaquero JM, Cardona F, Casanueva F, Tinahones FJ (2013) Gut microbiota composition in male rat models under different nutritional status and physical activity and its association with serum leptin and ghrelin levels. PLoS One 8, e65465.

[35] Westfall S, Lomis N, Kahouli I, Dia SY, Singh SP, Prakash S (2017) Microbiome, probiotics and neurodegenerative diseases: Deciphering the gut brain axis. Cell Mol Life Sci 74, 3769-3787.

[36] Song N, Wang W, Jia F, Du X, Xie A, He Q, Shen X, Zhang J, Rogers JT, Xie J, Jiang H (2017) Assessments of plasma ghrelin levels in the early stages of parkinson's disease. Mov Disord 32, 1487-1491.

[37] Fu Y, Ito M, Fujita Y, Ito M, Ichihara M, Masuda A, Suzuki Y, Maesawa S, Kajita Y, Hirayama M, Ohsawa I, Ohta S, Ohno K (2009) Molecular hydrogen is protective against 6hydroxydopamine-induced nigrostriatal degeneration in a rat model of Parkinson's disease. Neurosci Lett 453, 81-85.

[38] Fujita K, Seike T, Yutsudo N, Ohno M, Yamada H, Yamaguchi H, Sakumi K, Yamakawa Y, Kido MA, Takaki A, Katafuchi T, Tanaka Y, Nakabeppu Y, Noda M (2009) Hydrogen in drinking water reduces dopaminergic neuronal loss in the 1-methyl-4-phenyl-1,2,3,6-tetrahydropyridine mouse model of Parkinson's disease. PLoS One 4, e7247.

[39] Yoritaka A, Takanashi M, Hirayama M, Nakahara T, Ohta $\mathrm{S}$, Hattori N (2013) Pilot study of $\mathrm{H}_{2}$ therapy in Parkinson's disease: A randomized double-blind placebo-controlled trial. Mov Disord 28, 836-839.

[40] Turnbaugh PJ, Ley RE, Hamady M, Fraser-Liggett CM, Knight R, Gordon JI (2007) The human microbiome project. Nature 449, 804-810.

[41] Cattaneo A, Cattane N, Galluzzi S, Provasi S, Lopizzo N, Festari C, Ferrari C, Guerra UP, Paghera B, Muscio C, Bianchetti A, Volta GD, Turla M, Cotelli MS, Gennuso M, Prelle A, Zanetti O, Lussignoli G, Mirabile D, Bellandi D, Gentile S, Belotti G, Villani D, Harach T, Bolmont T, Padovani A, Boccardi M, Frisoni GB (2017) INDIA-FBP Group Association of brain amyloidosis with pro-inflammatory gut bacterial taxa and peripheral inflammation markers in cognitively impaired elderly. Neurobiol Aging 49, 60-68.

[42] Vogt NM, Kerby RL, Dill-McFarland KA, Harding SJ, Merluzzi AP, Johnson SC, Carlsson CM, Asthana S, Zetterberg H, Blennow K, Bendlin BB, Rey FE (2017) Gut microbiome alterations in Alzheimer's disease. Sci Rep 7, 13537.

[43] Finegold SM, Molitoris D, Song Y, Liu C, Vaisanen M, Bolte E, McTeague M, Sandler R, Wexler H, Marlowe EM, Collins 
MD, Lawson PA, Summanen P, Baysallar M, Tomzynski TJ, Read E, Johnson E, Rolfe R, Nasir P, Shah H, Haake DA, Manning P, Kaul A (2002) Gastrointestinal microflora studies in late-onset autism. Clin Infect Dis 35, S6-S16.

[44] Finegold SM (2011) Desulfovibrio species are potentially important in regressive autism. Med Hypotheses 77, 270274.

[45] Finegold SM, Downes J, Summanen PH (2012) Microbiology of regressive autism. Anaerobe 18, 260-262.

[46] Jangi S, Gandhi R, Cox LM, Li N, von Glehn F, Yan R, Patel B, Mazzola MA, Liu S, Glanz BL, Cook S, Tankou S, Stuart F, Melo K, Nejad P, Smith K, Topçuolu BD, Holden J, Kivisäkk P, Chitnis T, De Jager PL, Quintana FJ, Gerber GK, Bry L, Weiner HL (2016) Alterations of the human gut microbiome in multiple sclerosis. Nat Commun 7, 12015.

[47] Chen J, Chia N, Kalari KR, Yao JZ, Novotna M, Paz Soldan MM, Luckey DH, Marietta E V, Jeraldo PR, Chen X, Weinshenker BG, Rodriguez M, Kantarci OH, Nelson H, Murray JA, Mangalam AK (2016) Multiple sclerosis patients have a distinct gut microbiota compared to healthy controls. Sci $\operatorname{Rep}$ 6, 28484.

[48] Tremlett H, Fadrosh DW, Faruqi AA, Zhu F, Hart J, Roalstad S, Graves J, Lynch S, Waubant E (2016) US Network of Pediatric MS Centers Gut microbiota in early pediatric multiple sclerosis: A case-control study. Eur J Neurol 23, 1308-1321.

[49] Miyake S, Kim S, Suda W, Oshima K, Nakamura M, Matsuoka T, Chihara N, Tomita A, Sato W, Kim S-W, Morita H, Hattori M, Yamamura T (2015) Dysbiosis in the gut microbiota of patients with multiple sclerosis, with a striking depletion of species belonging to clostridia XIVa and IV clusters. PLoS One 10, e0137429.

[50] Cantarel BL, Waubant E, Chehoud C, Kuczynski J, DeSantis TZ, Warrington J, Venkatesan A, Fraser CM, Mowry EM (2015) Gut microbiota in multiple sclerosis: Possible influence of immunomodulators. J Investig Med 63, 729-734.

[51] Dalile B, Van Oudenhove L, Vervliet B, Verbeke K (2019) The role of short-chain fatty acids in microbiota-gut-brain communication. Nat Rev Gastroenterol Hepatol 16, 461478.

[52] Savica R, Carlin JM, Grossardt BR, Bower JH, Ahlskog JE, Maraganore DM, Bharucha AE, Rocca WA (2009) Medical records documentation of constipation preceding Parkinson disease: A case-control study. Neurology 73, 1752-1758.

[53] Scheperjans F (2016) Gut microbiota, 1013 new pieces in the Parkinson's disease puzzle. Curr Opin Neurol 29, 773780.

[54] Sharkey KA, Savidge TC (2014) Role of enteric neurotransmission in host defense and protection of the gastrointestinal tract. Auton Neurosci 181, 94-106.

[55] Zhao Y, Yu Y-B (2016) Intestinal microbiota and chronic constipation. Springerplus 5, 1130.

[56] Barichella M, Severgnini M, Cilia R, Cassani E, Bolliri C, Caronni S, Ferri V, Cancello R, Ceccarani C, Faierman S, Pinelli G, De Bellis G, Zecca L, Cereda E, Consolandi C, Pezzoli G (2019) Unraveling gut microbiota in Parkinson's disease and atypical parkinsonism. Mov Disord 34, 396-405.

[57] Boertien JM, Pereira PAB, Aho VTE, Scheperjans F (2019) Increasing comparability and utility of gut microbiome studies in Parkinson's disease: A systematic review. J Parkinsons Dis, 1-15.

[58] Costea PI, Zeller G, Sunagawa S, Pelletier E, Alberti A, Levenez F, Tramontano M, Driessen M, Hercog R, Jung FE, Kultima JR, Hayward MR, Coelho LP, Allen-Vercoe E, Bertrand L, Blaut M, Brown JRM, Carton T, Cools-Portier
S, Daigneault M, Derrien M, Druesne A, De Vos WM, Finlay BB, Flint HJ, Guarner F, Hattori M, Heilig H, Luna RA, Van Hylckama Vlieg J, Junick J, Klymiuk I, Langella P, Le Chatelier E, Mai V, Manichanh C, Martin JC, Mery C, Morita H, O'toole PW, Orvain C, Patil KR, Penders J, Persson S, Pons N, Popova M, Salonen A, Saulnier D, Scott KP, Singh B, Slezak K, Veiga P, Versalovic J, Zhao L, Zoetendal EG, Ehrlich SD, Dore J, Bork P (2017) Towards standards for human fecal sample processing in metagenomic studies. Nat Biotechnol 35, 1069-1076.

[59] Tetz G, Brown SM, Hao Y, Tetz V (2018) Parkinson's disease and bacteriophages as its overlooked contributors. Sci Rep 8, 10812.

[60] Gough E, Shaikh H, Manges AR (2011) Systematic review of intestinal microbiota transplantation (fecal bacteriotherapy) for recurrent clostridium difficile infection. Clin Infect Dis 53, 994-1002.

[61] Drekonja D, Reich J, Gezahegn S, Greer N, Shaukat A, MacDonald R, Rutks I, Wilt TJ (2015) Fecal microbiota transplantation for Clostridium difficile infection. Ann Intern Med 162, 630 .

[62] Colman RJ, Rubin DT (2014) Fecal microbiota transplantation as therapy for inflammatory bowel disease: A systematic review and meta-analysis. J Crohn's Colitis $\mathbf{8}$, 1569-1581.

[63] Tian H, Ge X, Nie Y, Yang L, Ding C, McFarland L V, Zhang X, Chen Q, Gong J, Li N (2017) Fecal microbiota transplantation in patients with slow-transit constipation: A randomized, clinical trial. PLoS One 12, e0171308.

[64] Xu M-Q, Cao H-L, Wang W-Q, Wang S, Cao X-C, Yan F, Wang B-M (2015) Fecal microbiota transplantation broadening its application beyond intestinal disorders. World $J$ Gastroenterol 21, 102-111.

[65] Huang H, Xu H, Luo Q, He J, Li M, Chen H, Tang W, Nie Y, Zhou Y (2019) Fecal microbiota transplantation to treat Parkinson's disease with constipation: A case report. Medicine (Baltimore) 98, e16163.

[66] Sun M-F, Zhu Y-L, Zhou Z-L, Jia X-B, Xu Y-D, Yang Q, Cui C, Shen Y-Q (2018) Neuroprotective effects of fecal microbiota transplantation on MPTP-induced Parkinson's disease mice: Gut microbiota, glial reaction and TLR4/TNF$\alpha$ signaling pathway. Brain Behav Immun 70, 48-60.

[67] Santens P Fecal Microbiota Transplantation for Parkinson's Disease - Full Text View - ClinicalTrials.gov n.d. Accessed on 18 September 2019. Available at: https://clinicaltrials.gov/ct2/show/NCT03808389.

[68] Wilson BC, Vatanen T, Cutfield WS, O'Sullivan JM (2019) The super-donor phenomenon in fecal microbiota transplantation. Front Cell Infect Microbiol 9, 2.

[69] Parthasarathy G, Chen J, Chen X, Chia N, O'Connor HM, Wolf PG, Gaskins HR, Bharucha AE (2016) Relationship between microbiota of the colonic mucosa vs feces and symptoms, colonic transit, and methane production in female patients with chronic constipation. Gastroenterology 150, 367-379.e1.

[70] Kellermayer R (2019) Fecal microbiota transplantation: Great potential with many challenges. Transl Gastroenterol Hepatol 4, 40-40.

[71] Costello SP, Hughes PA, Waters O, Bryant R V, Vincent $\mathrm{AD}$, Blatchford P, Katsikeros R, Makanyanga J, Campaniello MA, Mavrangelos C, Rosewarne CP, Bickley C, Peters C, Schoeman MN, Conlon MA, Roberts-Thomson IC, Andrews JM (2019) Effect of fecal microbiota transplantation on 8-week remission in patients with ulcerative colitis: A randomized clinical trial. JAMA 321, 156-164. 
[72] Barichella M, Pacchetti C, Bolliri C, Cassani E, Iorio L, Pusani C, Pinelli G, Privitera G, Cesari I, Faierman SA, Caccialanza R, Pezzoli G, Cereda E (2016) Probiotics and prebiotic fiber for constipation associated with Parkinson disease. Neurology 87, 1274-1280.

[73] Cassani E, Privitera G, Pezzoli G, Pusani C, Madio C, Iorio L, Barichella M (2011) Use of probiotics for the treatment of constipation in Parkinson's disease patients. Minerva Gastroenterol Dietol 57, 117-121.

[74] Tamtaji OR, Taghizadeh M, Daneshvar Kakhaki R, Kouchaki E, Bahmani F, Borzabadi S, Oryan S, Mafi A, Asemi Z (2019) Clinical and metabolic response to probiotic administration in people with Parkinson's disease: A randomized, double-blind, placebo-controlled trial. Clin Nutr 38, 1031-1035.

[75] van Nood E, Speelman P, Nieuwdorp M, Keller J (2014) Fecal microbiota transplantation: Facts and controversies. Curr Opin Gastroenterol 30, 34-39.

[76] Cantu-Jungles TM, Rasmussen HE, Hamaker BR (2019) Potential of prebiotic butyrogenic fibers in Parkinson's disease. Front Neurol 10, 663.
[77] Important Safety Alert Regarding Use of Fecal Microbiota for Transplantation and Risk of Serious Adverse Reactions Due to Transmission of Multi-Drug Resistant Organisms | FDA n.d. Accessed on 18 September 2019. Available at: https://www.fda.gov/vaccines-blood-biologics/safetyavailability-biologics/important-safety-alert-regarding-usefecal-microbiota-transplantation-and-risk-serious-adverse.

[78] Besselink MG, van Santvoort HC, Buskens E, Boermeester MA, van Goor H, Timmerman HM, Nieuwenhuijs VB, Bollen TL, van Ramshorst B, Witteman BJ, Rosman C, Ploeg RJ, Brink MA, Schaapherder AF, Dejong CH, Wahab $\mathrm{PJ}$, van Laarhoven $\mathrm{CJ}$, van der Harst E, van Eijck $\mathrm{CH}$, Cuesta MA, Akkermans LM, Gooszen HG (2008) Dutch acute pancreatitis study group probiotic prophylaxis in predicted severe acute pancreatitis: A randomised, doubleblind, placebo-controlled trial. Lancet 371, 651-659.

[79] Kothari D, Patel S, Kim S-K (2019) Probiotic supplements might not be universally-effective and safe: A review. Biomed Pharmacother 111, 537-547. 